\title{
Using a Critical Literacy Approach in the EFL class
}

Mariana Farralelli

\begin{abstract}
Thinking critically is an ability which is to be developed in the EFL class as a result of the generalized process of globalization, immigration and poverty. It is essential for teachers to be aware of the fact that tolerance, dialogue among cultures and deconstruction of texts need to be exercised so that students can dissect dominant discourses and allow for diversity knocking down stereotypes. What follows is a detailed guide of all those aspects teachers should take into account if they are to indicate in their students a critical way to approach reality.
\end{abstract}

Key words: critical literacy, thinking skills, power relations, discourse

\section{Introduction}

There are a number of phenomena taking place in the $21^{\text {st }}$ century world which require new capabilities and even demand specific mental abilities. Raising our students' critical thinking skills has become in the recent years a compelling need. The seemingly inexorable technological race, cultural, industrial and financial globalization of societies, migration and cases of massive poverty are all to be dealt with and processed by a new type of individual which is both an inhabitant of a country and a citizen of the world.

Gender issues as well as class and cultural conflict and exchange are categories which need to be redefined and surfaced in the EFL class so that our students can cope with -and/or survive- in the new constantly changing global reality. Given this context, the thesis I advance in the article is that Critical Literacy (CL) seems to offer one of the most resourceful ways in which teachers and students can get together and analyze, question and finally dwell in today's dynamic world.
I will devote the following sections to the close study of how CL can be used as a tool to explore power relations, texts and ideology and, at the same time, allow for independent thinking and diversity. The article will move from the abstract to the concrete: I will start by outlining the key concepts to be used -critical literacy, power, discourse, ideology-, then I will continue by connecting them to a specific theoretical framework -Freire's pedagogy, Derrida's deconstructivism- and finally I will give it a close by addressing both with some concrete examples when analyzing texts, and the OSDE (Open Spaces for Dialogue and Enquiry) methodology which is a CL model for teachers to draw on.

\section{CL and power relations}

The concept of CL is mainly concerned with the idea that language and power are inextricably related and that meaning, as Thompson (1984) puts it "serves to sustain relations of domination" (p.35). Within the field of CL language and, more specifically, discourse are not neutral, on the contrary, they amount to effective means of reproducing and maintaining 
power relations. In this sense Terry Eagleton (1991) asserts that we all carry "social and political battles at the level of signs, meanings and representations" (p. 11). This reinforces the idea that language does things and is not only an aseptic system of signs used for communication. Dissecting meaning then and deconstructing representations are possible ways in which power relations can be analyzed.

Getting students -and teachers- to critically reflect upon their taken-for-granted assumptions is one of the first steps towards the development of effective and functional critical thinking skills. This level of reflection can only be reached if first they understand that the world they experience every day is just one more among many other interpretations of reality.

Their manner of thinking and valuing is therefore put in perspective and identified as part of a more comprehensive whole in which there are other viewpoints as interesting to explore as the one they feel they belong to.

\section{$C L$ and texts}

From a critical standpoint and on a more concrete level, texts -literary, but also audiovisual, photographic, advertising and even TV commercials- are seen as biased entities which offer just a partial interpretation of reality; they express a certain clipping of an issue, a historically and culturally bound glimpse of the world. Students are consequently encouraged to identify and recognize the assumptions behind them.

To understand and exemplify how interpretations change across cultures we can explore the case of how an animal, the cow, is perceived differently in two diverse settings. In Argentina, beef is an essential part of our traditional cuisine: thousands of tourists taste it in exquisite combinations every year and most families and friends gather around a barbecue on Sundays. However, for religious reasons in India and Nepal the cow is considered a sacred animal which is revered as a source of life and as a result forbidden for human consumption. The animal itself, needless to say, is the same but what changes is how it is regarded and signified. Nutritional source and symbol of national cookery art in one case, centre of religious beliefs and practices on the other, the symbolic content is different in the two cultures.

Should students believe that theirs is a better perspective than that predominant in another country? Should they feel that both views are equally valuable and enriching? Here is where CL allows for tolerance and dialogue among cultures, an essential demand in the global world.

\section{CL and ideology}

The way through which certain ideas become natural is usually unconscious. French Philosopher, Althusser (1971) defined ideology as a process "which takes place behind our backs". Everything happens in a secret and unconscious way. We are provided with a set of ideas to understand the world and our place in it according to our class, race and gender. Ideology is the lens through which we see, interpret and experience the world.

Exploring these naturalized beliefs requires a lot of work and our own estrangement from all the perceptions and ideas we are used to. We need to take a distance, exert ourselves to produce an intellectual separation from all those things that are normal in the world that surrounds us every day.

\section{CL, discourse and power}

Becoming estranged is the best way to surface assumptions, that is, to make all these naturalized pre-concepts become conscious to us so that we can analyze them critically. To go even deeper into this section we can resort to the concept of discourse as defined by another French philosopher, Foucault (1972), who understood discourse as a social construction which claims to be a representation of reality.

In his analysis Foucault introduces the element of power to identify its decisive influence in the establishment of certain representations of the world. It is through power that some specific discourses become dominant to the detriment of others. Very briefly: in general, in Western societies we can say the dominant discourse is 
usually heterosexual, male, white and middle class. Women, blacks, homosexuals and the poor are left as outsiders in the periphery.

A critical approach to a text should dissect the dominant discourse and treat it no longer as the only possible interpretation, but as one among many others.

\section{CL: reading against the grain}

Given that knowledge is partial and produced within the context of a culture and that meaning is unstable and incomplete and can be questioned and redistributed dominant perspectives can be resisted. A plural frame, which accepts a diversity of approaches, is the key to read against texts and reinterpret them: reading critically is the first step to reading the world critically.

\section{CL and OSDE methodology}

The way I myself have been trying to put CL into practice these years consists of a quite recent approach developed by the Centre for the Study of Social and Global Justice at the University of Nottingham in the UK and its name, OSDE, is an acronym which stands for Open Spaces for Dialogue and Enquiry. The interesting thing about OSDE methodology is that it offers teachers and students very clear lines of thought together with pilot activities which serve as models to be applied and adapted to each pedagogic context in particular. The purpose of this section, therefore, is to track down its theoretical basis and at the same time cast the eyes on how OSDE interrelates, interacts with and questions those same grounds it grows roots on.

Taking the theoretical background into the classroom and adopting a critical perspective requires a lot of effort. For CL to take place into the classroom some steps need to be followed. Critical thinking skills do not 'grow' in our students from one day to another. They need to be developed gradually and in a consistent and systematic way. The democratic approach in which every student's voice is heard and considered, and the role of the teacher as facilitator are key elements in this process which is bound to encounter conflict and personal or group resistance.
It is possible to trace the conceptual framework OSDE draws on but that would be a simple example of a determinist attempt. The path we have decided to take in the analysis addresses the methodology from two different perspectives. The first one tries to comprehend the approach through the study of its three Ground Principles for Dialogue which briefly state that discourse productions are all legitimate, but also incomplete and subject to questioning. This stage will let us access OSDE from its core values and underlying ideas and determine the possible connections - and interactions- with a broad variety of theoretical frameworks.

The next step will consist of analyzing what are called OSDE's expected learning outcomes: Critical Literacy and Independent Thinking. This is meant as a way to direct the enquiry to a more practical aspect of the methodology where its conversation with other theories becomes more apparent.

\section{OSDE's theoretical background}

As a general starting point we could say the most evident connection between CL and OSDE is that with the Brazilian theorist and pedagogue Paulo Freire, whose most fruitful contribution consists of changing the focus of the pedagogic practice from the teacher to the student, himself or herself considered the centre and new protagonist of the education process.

Freire (1970) understood the process of education not as a mere transmission of concepts aimed at filling the student with supplies provided by the teacher -which he called 'banking' education. He conceived a new way of thinking such process as one where reciprocity is possible and where the traditional dichotomy educator-student was suppressed to promote mutual learning and collaboration. His Marxist lineage was present in his conception of the schooling institution and the classic pedagogic relation as an instrument for domination and power, but also in his faith in social transformation as the key to change the world.

According to Freire's critical pedagogy, a radical change had to be made in the way educators and students interacted with each other within the 
class. The power relation which held the former as a dominant agent over the latter and thus reinforced the status quo and the hegemonic discourses had to be overturned. It was only by legitimizing their own beliefs and actions that, in Freire's view, the lower classes would one day change their lives and transform society.

This point is clearly expressed in OSDE's first principle which asserts that what every individual produces -discourses, practices, beliefs- in their own context is valid and legitimate. Here, respect and tolerance for diversity are encouraged and specially emphasized. By means of this first principle OSDE creates a space where difference is accepted and contrast of views is even encouraged within a plural frame. The conflict is eventually overcome through the validation of those views, which are acknowledged by the members of the space.

This principle can also be linked to the main idea present in the ethnographic approach which basically proves that knowledge is produced within a culture and therefore is loaded with specific values and perceptions of reality that are perfectly legitimate to that context. Its most recognized exponent, the anthropologist Clifford Geertz (2000), defines culture as a frame where all actions and representations of reality make sense. As a consequence, for example, it is possible to read the wink of an eye as a signal of a joke but also as a sign of conflict depending on the culture/context where it occurs. It is only by accepting diversity that the ethnocentric interpretation can be set aside and the new or different version comprehended and its richness valued.

The originality offered by OSDE is that it puts into practice all those ideas presented only in theoretical terms. Within the OSDE class students engage with difference and literally feel and practice various degrees of cultural awareness. They are empowered to place themselves in the centre of the learning process and address conflict and diversity in an ethical manner. Although they may not be acquainted with either Freire's or Geertz's theories, they actually enact them bringing them to life in the specific context of their class situation.
What antecedes takes us to the second principle which is in part the outcome of the previous one. That all knowledge is partial and incomplete is visibly derived from its 'contextual' nature. When interacting with diversity the inclusion of different perspectives is a requirement especially when it comes to go beyond the limits traced by our own culture and experience. For the space created by OSDE to be open and plural there has to be an explicit understanding that no perspective will be better or more appropriate than the other, not even the teacher's.

This concern is part of the post structuralist interest in the constitution of knowledge as incomplete and part of power relations. The French philosopher Michel Foucault (1972) introduced the element of power to identify its decisive influence in the establishment of certain interpretations of the world to the detriment of others. As a result, the dominant discourse arises and claims itself to be the most precise representation of reality relegating the others to a lower position (Foucault, 1998).

Within OSDE all generalization and stereotyping is pulled down and succumbs to the firm belief that although identities tend to be standardized and taken for granted in the globalized world, they should be deconstructed and examined critically. As the educator, now facilitator, is no longer the centre of the attention in the classroom, his or her answer is no longer the 'right' answer to be taken into account. His/Hers is one more contribution among others which are equally valid.

There is a clear condition when deciding to apply OSDE: everyone -both educators and studentsneeds to understand that no perspective is enough to address reality. Given that no discourse is sutured, then individuals are invited to cooperate and collaborate in the consideration of each and every position. What is enacted in this case is the possibility to interact with diversity. The purpose is not to get rid of those individual discourses in the name of a more totalizing or complete one. The aim is to read the world and interact with each other in a more responsible way. 
Considering the partial structure of knowledge, the third and last principle completes the formula by stating that all perspectives should be questioned. Being partial and incomplete, students but also educators are encouraged to challenge their own assumptions and established, naturalized practices.

Derrida's (1998) deconstructivist contribution is the one which promotes the critical approach to one's beliefs and taken for granted ideas. This critique, however, is not understood as a way of discarding one perspective to shift to another. Its main purpose is to open spaces for criticism and change, especially to understand how truths are produced and then installed as hegemonic or unique in a context where all points of view need be considered.

One of the most relevant possible outcomes of the methodology is the possibility, now real and very close to students and the teacher, to confront their own beliefs and dissect them not just to get rid of them but to address them critically. The result is that in the deconstruction of their own assumptions individuals understand how and why ideas came to be true to them and then decide whether or not they need to be revised or altered.

\section{CL and independent thinking}

These three principles and the conceptual basis they draw on feature the two most important objectives OSDE seeks to achieve: Critical Literacy and Independent Thinking.

Critical Literacy establishes a connection with the axioms held by what is generally known as Critical Theory. Traditionally, it has been identified with a critique of modernity and capitalism. When connected with social theory it is commonly associated with the German Frankfurt School which housed major social scientists such as Walter Benjamin, Herbert Marcuse and Max Horkheimer, among others. As a result of its German constitution, it received the influence of the two most prominent thinkers of the time: Karl Marx and Max Weber and thus considered the economic and material aspects of society as key elements to be analyzed by theory.

The main assumption is that since power and forces are unequal in society, those who are not favoured by the hegemonic sectors ought to struggle to transform their disadvantageous situation.

Independent Thinking comes as a result of the preceding process in which individuals, now aware of how identities and social practices work, seek change in a more autonomous way. Therefore, they are enabled to fight against dogmatisms and dominant perspectives and explore their own culture sharply.

The critical element OSDE brings to the class is empowering students to address their context and reality equipped with more tools to surface taken for granted ideas and assumptions. Against the uniformity of gender, race and class stereotypes, both students and educators are offered the opportunity to think otherwise and get involved with alternative representations of the world and themselves.

\section{CL and OSDE: some concrete questions}

Accepting diversity naturally leads to the questioning of stereotypes which are now deconstructed and examined critically. Questioning literally means asking questions. Taking into consideration what Nodelman and Reimer (1992) suggest in The Pleasures of Children's Literature, these are some possible questions we can ask ourselves before a text so that we approach it critically with our students to deconstruct stereotypes:

How are social classes depicted? Is there any hierarchy in the social order that is accepted as natural?

How are women portrayed? Are they shown as sensitive, affectionate, nurturing and needing protection? Are male characters shown as their rational, strong and powerful counterpart? What happens when a woman presents some of these "tomb-boyish" qualities? Is she rejected by her peers? Is she perceived as odd? How is she treated as the plot unfolds?

Are there any distinctions made on grounds of ethnicity? Are Blacks presented as musical or athletic? The Jews all smart? The Asians 
all industrious? Does it take people from the mainstream to solve problems of people from minority groups? Who takes leadership and makes decisions? (p.116).

\section{A Brief Close}

One important point that is not to be missed is that the achievement of a critical understanding of reality and relations does not necessarily mean individuals are encouraged to drop their ideas and habits. Quite the contrary. The objective is to respect each other appreciating both differences and affinities.

When taking a CL approach to the class, the teacher's proposal of classroom work would be a film viewing session after which students analyse certain aspects of the film -how class and/or gender are depicted, for instance- or discuss race issues such as who has the power or who appears to be dependent of others to fulfill a need. The analysis of advertisements or the discussion TV commercials are other possibilities for both teachers and students to exchange their views and share perspectives.

Intellectual development and self-control are abilities which are also stimulated and cultivated together with tolerance and mutual esteem. As no discourse is meant to be superior to any other, then participants are promoted to exercise sensitivity and regard for diversity.

In this dialogue OSDE keeps with so many different approaches, the theory is refurbished and applied in contexts where it is rewritten again and again. This transformation is also a renovation process where students, educators and citizens rediscover their own culture and potentials and are empowered to change and question their reality and society itself.
Mariana Ferrarelli holds a BA in Communication Sciences from Universidad de Buenos Aires and three postgraduate courses in Investigation Methodology. She has taught both at secondary level and at higher education. She is currently a teacher at Lomas High School, a bilingual secondary school in Buenos Aires, and at Golden Crop English Teaching Centre, where she also delivers classes on A Level Literature, IGCSE Sociology and IGCSE History. She works transdisciplinarily with approaches ranging from Discourse Analysis and Linguistics to Cultural Studies and Gender Theory. Her research interests include Critical Literacy and how it can be applied in the ELT class.

\section{References}

Althusser, L. (1971). Essays on ideology. New York: New Left Books.

Derrida, J. (1998). Of grammatology. Baltimore: the Johns Hopkins University Press.

Eagleton, T. (1991). Ideology. London: Longman.

Foucault, M. (1978). The history of sexuality. London: Penguin.

Foucault, M. (1998). Las palabras y las cosas. Mexico: Siglo XXI Editores.

Foucault, M. (2002). The archaeology of knowledge. Cornwall: Routledge Classics.

Freire, P. (1970). Pedagogy of the oppressed. Montevideo: Tierra Nueva.

Geertz, C. (2000). Interpretation of cultures. USA: Basic Books.

Kramsch, C. (1998). Language and culture. China: Oxford University Press.

Nodelman, P. \& Reimer, M. (1992). The pleasures of children's literature.XXX: Allyn \& Bacon.

Thompson, J.B. (1984). Studies in the theory of ideology. Cambridge: Polity Press.

Truth and Reconciliation Commission (1998). Truth and reconciliation commission of South Africa report. Cape Town: Juta \& Co. 